\title{
FTIR nanobiosensors for Escherichia coli detection
}

\author{
Stefania Mura ${ }^{* 1,2,3, \S}$, Gianfranco Greppi ${ }^{1,4}$, Maria Laura Marongiu 4 , \\ Pier Paolo Roggero ${ }^{1}$, Sandeep P. Ravindranath ${ }^{2}$, Lisa J. Mauer ${ }^{5}$, \\ Nicoletta Schibeci ${ }^{3}$, Francesco Perria ${ }^{6}$, Massimo Piccinini ${ }^{7}$, Plinio Innocenzi ${ }^{8}$ \\ and Joseph Irudayaraj ${ }^{2}$
}

\section{Full Research Paper}

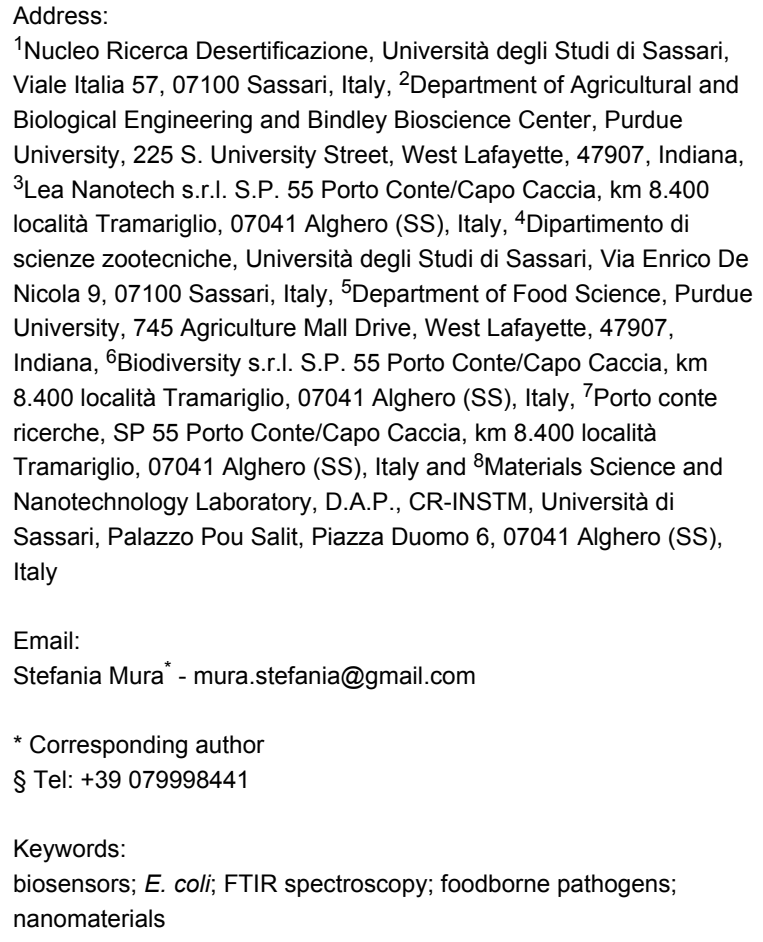

${ }^{1}$ Nucleo Ricerca Desertificazione, Università degli Studi di Sassari, Viale Italia 57, 07100 Sassari, Italy, ${ }^{2}$ Department of Agricultural and Biological Engineering and Bindley Bioscience Center, Purdue University, 225 S. University Street, West Lafayette, 47907, Indiana, ${ }^{3}$ Lea Nanotech s.r.I. S.P. 55 Porto Conte/Capo Caccia, km 8.400 località Tramariglio, 07041 Alghero (SS), Italy, ${ }^{4}$ Dipartimento di scienze zootecniche, Università degli Studi di Sassari, Via Enrico De Nicola 9, 07100 Sassari, Italy, ${ }^{5}$ Department of Food Science, Purdue University, 745 Agriculture Mall Drive, West Lafayette, 47907, Indiana, ${ }^{6}$ Biodiversity s.r.I. S.P. 55 Porto Conte/Capo Caccia, km 8.400 località Tramariglio, 07041 Alghero (SS), Italy, ${ }^{7}$ Porto conte ricerche, SP 55 Porto Conte/Capo Caccia, km 8.400 località Tramariglio, 07041 Alghero (SS), Italy and ${ }^{8}$ Materials Science and Nanotechnology Laboratory, D.A.P., CR-INSTM, Università di Sassari, Palazzo Pou Salit, Piazza Duomo 6, 07041 Alghero (SS), Italy

Email:

Stefania Mura* - mura.stefania@gmail.com

* Corresponding author

$\S$ Tel: +39079998441

Keywords:

biosensors; E. coli; FTIR spectroscopy; foodborne pathogens;

nanomaterials

Beilstein J. Nanotechnol. 2012, 3, 485-492. doi:10.3762/bjnano.3.55

Received: 06 March 2012

Accepted: 13 June 2012

Published: 03 July 2012

This article is part of the Thematic Series "Nanostructures for sensors, electronics, energy and environment".

Associate Editor: N. Motta

(C) 2012 Mura et al; licensee Beilstein-Institut. License and terms: see end of document.

\begin{abstract}
Infections due to enterohaemorrhagic E. coli (Escherichia coli) have a low incidence but can have severe and sometimes fatal health consequences, and thus represent some of the most serious diseases due to the contamination of water and food. New, fast and simple devices that monitor these pathogens are necessary to improve the safety of our food supply chain. In this work we report on mesoporous titania thin-film substrates as sensors to detect E. coli O157:H7. Titania films treated with APTES ((3-aminopropyl)triethoxysilane) and GA (glutaraldehyde) were functionalized with specific antibodies and the absorption properties monitored. The film-based biosensors showed a detection limit for E. coli of $1 \times 10^{2} \mathrm{CFU} / \mathrm{mL}$, constituting a simple and selective method for the effective screening of water samples.
\end{abstract}




\section{Introduction}

Foodborne illness is primarily caused by pathogenic microorganisms among which Campylobacter, Salmonella, Listeria monocytogenes, and Escherichia coli O157: $\mathrm{H} 7$ are responsible for the majority of foodborne outbreaks [1,2], and most of the recalls of food products have implicated these pathogens [3]. In particular E. coli is a typical inhabitant of the human intestinal tract; however, the strain E. coli $\mathrm{O} 157: \mathrm{H} 7$, one of the most dangerous foodborne pathogens [4], causes diseases that may lead to death [5]. Sensors to detect these pathogens, especially in ground beef and raw milk [6], are critical.

The conventional methods for the detection and identification of pathogens $[7,8]$ are mostly based on (i) culture and colony counting methods (which involve counting of bacteria) [9]; (ii) immunology-based methods (which involve antigen-antibody interactions) [10]; and (iii) the polymerase chain reaction (PCR) method (which involves DNA analysis) [11,12]. While these methods are sensitive and can recognize pathogens, the type of organism and the number of colonies in a qualitative and quantitative manner, they are not efficient because of the enrichment step necessary to detect pathogens in low numbers, to comply with the safety regulations of the food and water supply chain. In addition, these methods are expensive, complicated, timeconsuming, and require skilled personnel with expertise in molecular biology.

To overcome these problems, devices that can be used in situ, and that are simple, highly sensitive, inexpensive and rapid are attractive because they can be used for rapid screening of different samples for timely detection of these pathogenic agents. In fact monitoring food quality and safety attributes, by using new detection methods that have the potential to be sensitive and rapid [13], is important to prevent and identify problems related to health and safety. Lately, micro- and nanosystems for bacteria and food sample analysis have been developed as innovative tools for the detection of foodborne pathogens in the food and drink industries [14-21]. In particular, different optical biosensors were created for rapid detection of pathogenic bacteria, using fluorescence or surface plasmon resonance (SPR) because of their sensitivity [22,23].

For fluorescence analysis, antibodies (Ab) are conjugated with fluorescent compounds and used in combination with classical techniques (ELISA, PCR). With these biosensors overnight culture is required, leading to a long time for the analysis, while SPR is a powerful and complex technique, which unfortunately requires specialized staff, and costly and large equipment [24,25]. To overcome these limitations the aim of the present work is to develop a simple new nanodevice capable of detecting pathogens in low concentration and suitable for a fast real-time monitoring, using Fourier transform infrared (FTIR) spectroscopy as an optical transduction method.

\section{Experimental Chemicals}

All commercially available solvents and reagents were used without further purification. Titanium tetrachloride $\left(\mathrm{TiCl}_{4}\right.$, $>98 \%$ ), anhydrous ethanol (EtOH, $>99.9 \%$ ), bidistilled water, acetone $(>99.8 \%)$, and toluene $(>99.5 \%)$, were purchased from Carlo Erba (Italy). Pluronic F-127 (cell culture test), (3-aminopropyl)triethoxysilane (APTES, >98\%), glutaraldehyde (GA Grade I, $50 \%$ in $\mathrm{H}_{2} \mathrm{O}$, specially purified for use as an electron microscopy fixative or other sophisticated use) were purchased from Sigma Aldrich (Germany). E. coli O157:H7 and E. coli K12 were obtained from the bacteria collection at Purdue University (Agricultural and Biological Engineering). BHI agar, PCA, and LB were purchased from Teknova (Hollister, CA). Bac-trace affinity purified antibodies goat anti-E. coli $\mathrm{O} 157: \mathrm{H} 7$ were purchased from Kirkegaard and Perry Laboratories Inc. (Gaithersburg, MD). Silicon wafers (test grade, p-type boron doped, diameter 4", thickness 475-575 $\mu \mathrm{m}$, (100) oriented (one side polished and one side etched) were obtained from Jocam (Italy).

\section{Film preparation}

Titania $\left(\mathrm{TiO}_{2}\right)$ thin films were prepared by dipping silicon wafers in a solution composed of $\mathrm{TiCl}_{4} /$ Pluronic $\mathrm{F} 127 / \mathrm{H}_{2} \mathrm{O}$ / EtOH (1:0.005:10:40) under controlled conditions of temperature and RH (relative humidity). Films were deposited with a dip coater, aged at room temperature ( $\mathrm{RH} 50 \%$ for $24 \mathrm{~h}$ ) and, to increase the inorganic polycondensation and stabilize the mesophase, the films were submitted to different firing steps at 60 , 120 and $200{ }^{\circ} \mathrm{C}$ for $24 \mathrm{~h}$ at each temperature in an oven at a heating rate of $10^{\circ} \mathrm{C} \cdot \mathrm{min}^{-1}$. The final calcination process to remove the organic template of these stabilized coatings was conducted at $350{ }^{\circ} \mathrm{C}$ for $3.5 \mathrm{~h}$ in air under static conditions at a heating rate of $10^{\circ} \mathrm{C} \cdot \mathrm{min}^{-1}$. In this way mesoporous titania thin films were obtained and characterized as described in a previous work of our group [26].

\section{Film functionalization}

The optimization of the functionalization with amino-groups was obtained by immersing the calcined films in a solution $0.2 \mathrm{M}$ of APTES in toluene for $24 \mathrm{~h}$ at $25^{\circ} \mathrm{C}$. The amino grafted films were carefully washed with toluene over several washing cycles and finally dried in air. The following functionalization of $\mathrm{TiO}_{2}$-APTES films with GA was obtained by immersing the films in GA $50 \%(\mathrm{v} / \mathrm{v})$ in water for $24 \mathrm{~h}$, washing with water and $\mathrm{EtOH}$ and drying at room temperature. Different experiments were realized, providing the immobiliz- 
ation of antibodies directly on titania thin films, on films functionalized with APTES, or on films functionalized with APTES and GA. Antibody solutions were prepared by dissolving $200 \mu \mathrm{L}$ of anti-E. coli $\mathrm{O} 157: \mathrm{H} 7$ in $800 \mu \mathrm{L}$ phosphate buffered saline (PBS) to achieve a final concentration of $50 \mu \mathrm{g} / \mathrm{mL}$, after which the films were covered with this solution for $15 \mathrm{~h}$ at $4{ }^{\circ} \mathrm{C}$. Finally the films were washed with PBS and water, and dried at room temperature. FTIR spectroscopy measurements were carried out for each step to monitor the chemical functionalization and the linking of antibodies to the films.

\section{Bacteria preparation}

E. coli $\mathrm{O} 157: \mathrm{H} 7$ and E. coli $\mathrm{K} 12$ were cultured on agar plates for $24 \mathrm{~h}$ then a single colony of each species was transferred into 10 culture tubes containing $5 \mathrm{~mL}$ each of Luria-Bertani medium (LB) and placed in an incubator at $37^{\circ} \mathrm{C}$, under shaking, for $18 \mathrm{~h}$, at $120 \mathrm{rpm}$. Then the tubes were centrifuged at $3500 \mathrm{rpm}$ for $10 \mathrm{~min}$, to obtain a pellet. Finally LB was removed from the tube and the cells were washed three times with sterile PBS to remove residual medium and resuspended in $3 \mathrm{~mL}$ PBS for binding experiments.

Serial dilutions of bacteria were prepared for the detection step. To validate the data, a standard method for the counting of pathogens was also used: the culture and colony counting method. To revitalize the culture of $E$. coli, a single colony was transferred in a test tube containing a nutrient broth and placed in an incubator for $24 \mathrm{~h}$ at $37{ }^{\circ} \mathrm{C}$. Then serial dilutions were carried out in sterile saline solution to a dilution of $10^{-7}$. Then $1 \mathrm{~mL}$ of solutions at a dilution of $10^{-6}$ and $10^{-7}$ were plated in a petri plate with plate count agar (PCA) by the inclusion method (in duplicate for each dilution). Finally, after cooling, the four plates were incubated at $37^{\circ} \mathrm{C}$ for $24 \mathrm{~h}$ and the colonies were counted.

Considering the dilution factor and the mean number of colonies counted in two plates at a dilution of $10^{-6}$, the concentration of bacteria in the initial nutrient broth was obtained and estimated to be $1.13 \times 10^{8}$ colony-forming units $(\mathrm{CFU}) / \mathrm{mL}$. For DNA analysis a standard method was used to identify the pathogen: real-time PCR. The instrumentation BioRad IQ5 was used for the analysis. After DNA extraction with the boiling method, PCR was carried out with a blank sample, a reference sample and the DNA extracted from $1 \mathrm{~mL}$ of nutrient broth; 50 cycles were programmed and an amplification at the 17 th cycle could be observed.

\section{Determination of the detection limits of $E$. coli O157:H7}

Functionalized titania thin films were incubated with freshly prepared anti-E. coli O157:H7 antibodies, and then different films were covered with $1 \mathrm{~mL}$ of $E$. coli $\mathrm{O} 157: \mathrm{H} 7$ suspension at concentrations ranging between $10^{8}$ and $10 \mathrm{CFU} / \mathrm{mL}$ for $30 \mathrm{~min}$, to allow the binding to take place. Finally these films were washed and dipped for $15 \mathrm{~min}$ in PBS solution, washed with PBS and water, dried in air at room temperature and finally analysed by FTIR spectroscopy to determine the sensitivity of the method. Colony micrographs of these films were collected. Some tests with E. coli $\mathrm{K} 12$ were carried out to monitor the selectivity of the device.

\section{Film characterization}

Mesoporous titania thin films were characterized with a Nicolet Nexus FTIR spectrophotometer equipped with a $\mathrm{KBr}-\mathrm{DTGS}$ detector and a $\mathrm{KBr}$ beam splitter. The measurements were carried out in the range of $4000-700 \mathrm{~cm}^{-1}$ with 256 scans at $4 \mathrm{~cm}^{-1}$ resolution. The detector was cooled with liquid nitrogen for $60 \mathrm{~min}$ before data collection and also during the measurements.

The spectra of films deposited on silicon wafers were obtained in transmission mode. The background was recorded by using a silicon substrate. Atomic force microscopy (AFM) measurements were taken on titania films with an Asylum Research 3-D AFM in contact mode. An olympus BX-51 optical microscope with a $100 \times$ objective was used to collect microscopic images of films after pathogen immobilization.

\section{Results and Discussion}

An optical biosensor was developed for the detection of pathogenic E. coli O157:H7, by using FTIR spectroscopy to provide mid-infrared fingerprints of pathogens present in buffer. The spectroscopic fingerprint of pathogens originates from the various functional groups related to proteins, lipids, and carbohydrates, and their mid-infrared (MIR) spectra can be used for the identification and structural characterization of different pathogens and subspecies [27]. MIR spectra are additive and sensitive, and allow the fingerprinting and quantification of the pathogen of interest, transforming the traditional devices into biosensing systems with high sensitivity.

In particular, mesoporous titania thin films synthesized with the sol-gel method, were used to immobilize biomolecules (antibodies and pathogens) thanks to the high surface area due to their nano-organization, visible in a AFM image (Figure 1). This was possible due to a high control of the gelation process on the films and subsequent thermal treatments that avoided the denaturation of biomolecules in environments that have a high alcohol concentration and extreme $\mathrm{pH}$ values, hence obtaining ordered and reproducible substrates. With this objective, special attention was paid to the thermal treatments of films to completely remove the inorganic template, $\mathrm{EtOH}$ and $\mathrm{HCl}$. 


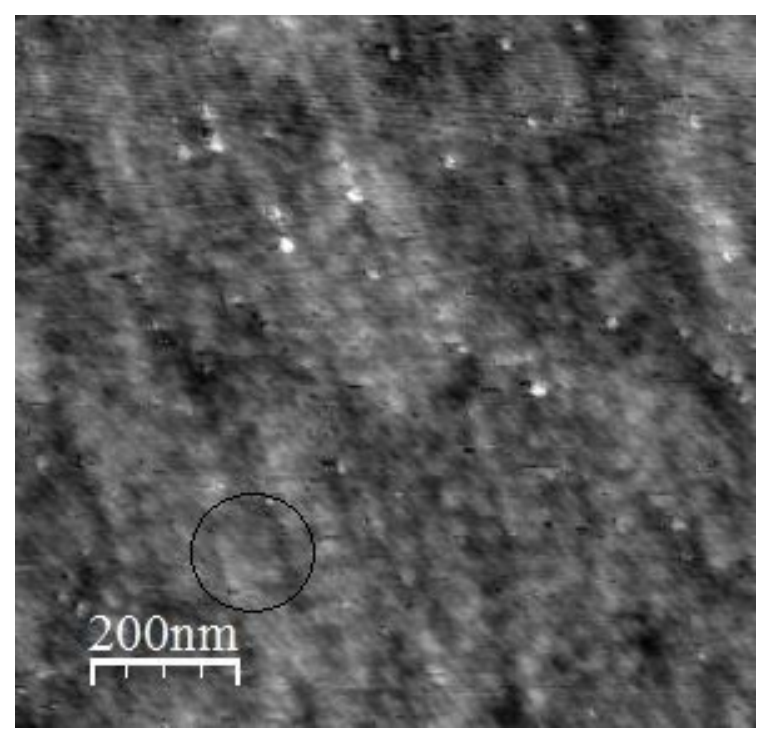

Figure 1: Microscopically ordered structure of a mesoporous titania film observed by AFM analysis.
Mesoporous titania was used as a substrate for the features described above, but also because it has excellent biocompatibility, stability (12 months at RT), and reproducibility, and can interact with biological molecules due to the formation of coordinated linkages between titania films, organic crosslinkers and amino or carboxyl groups of the antibodies or bacteria. In the present work the immobilization of bacteria was studied directly on titania films, on titania films functionalized with APTES and on titania films functionalized with APTES, GA and antibodies $(\mathrm{Ab})$.

\section{Detection of $E$. coli with}

\section{$\mathrm{TiO}_{2}$-APTES-GA-anti E. coli O157:H7-Ab}

The first method used illustrates the detection of $E$. coli O157:H7 through the immobilization of antibodies on titania films functionalized with APTES and GA. In the first step (Figure 2a) titania thin films were functionalized with APTES; in particular the spectra of the films before and after the functionalization process were reported. The peaks due to APTES (inset spectrum) have been attributed to $\mathrm{N}-\mathrm{H}$ stretching at $3300 \mathrm{~cm}^{-1}, \mathrm{~N}-\mathrm{CH}_{2}$ stretching around $2800 \mathrm{~cm}^{-1}, \mathrm{NH}_{2}$ a)

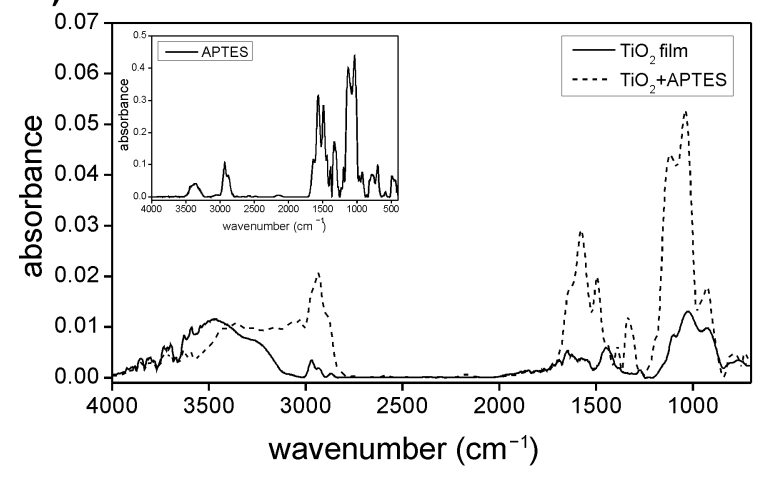

c)

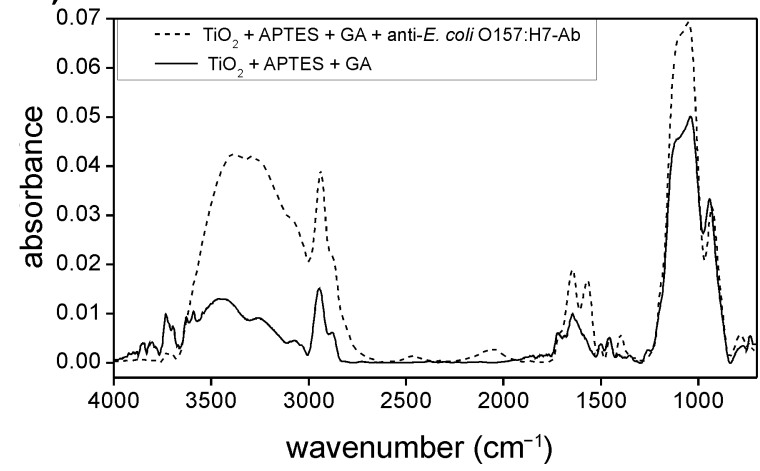

b)

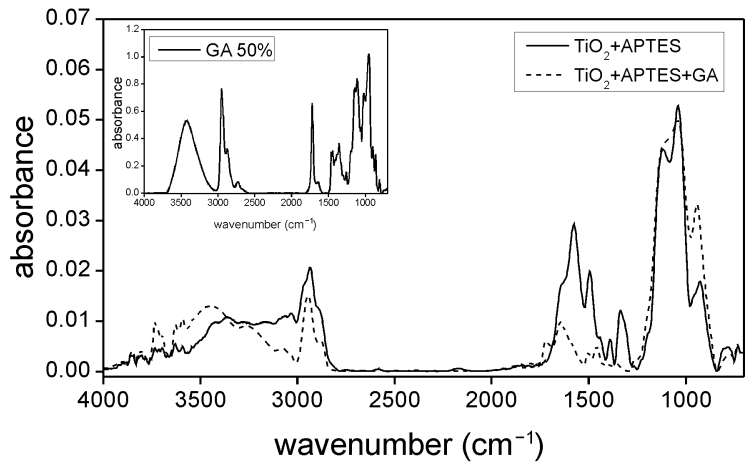

d)

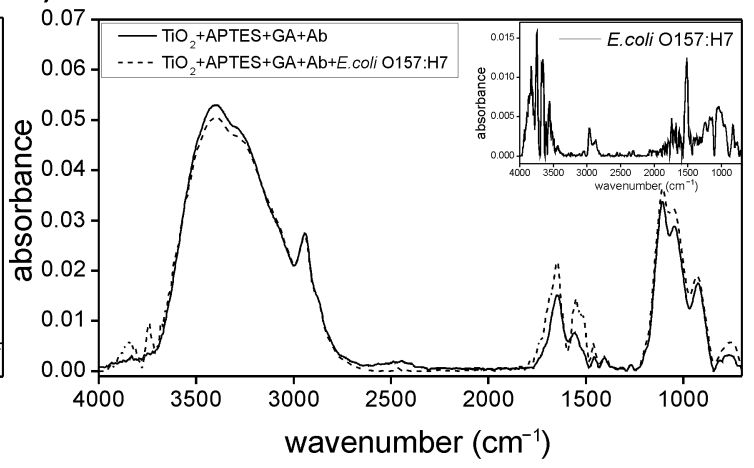

Figure 2: (a) FTIR spectrum of mesoporous titania thin films (solid line) and films functionalized with APTES (dashed line). The reference spectrum of APTES is reported in the inset. (b) FTIR spectrum of titania films functionalized with APTES (solid line) and after the linking of glutaraldehyde (dashed line); the spectrum of glutaraldehyde (GA) was reported in the inset for reference. (c) Spectrum of functionalized titania with APTES and GA (solid line) and after the linking of anti-E. coli O157:H7-antibody (dashed line). (d) FTIR spectrum of a titania film functionalized with APTES-GA-Ab (solid line) and after the immobilization of $E$. coli $\mathrm{O} 157: \mathrm{H} 7$ (dashed line); the reference spectrum of $E$. coli $\mathrm{O} 157: \mathrm{H} 7$ is provided in the inset. 
scissoring and $\mathrm{N}-\mathrm{H}$ bending at $1615 \mathrm{~cm}^{-1}$, aliphatic $\mathrm{C}-\mathrm{N}$ stretching at $1020-1220 \mathrm{~cm}^{-1}, \mathrm{NH}_{2}$ wagging and twisting at $850-750 \mathrm{~cm}^{-1}$ and $\mathrm{N}-\mathrm{H}$ wagging at $715 \mathrm{~cm}^{-1}$.

The second step was based on the reaction between APTES and GA, which was used to crosslink the APTES with antibodies due to the formation of an imine. Here, the terminal amino groups of APTES were changed to aldehydic groups that, in the following step, were covalently coupled with the amino groups of the antibody. The APTES-GA linking is shown in Figure $2 b$, in which the bands due to the formation of imines in the area between 1900 and $1600 \mathrm{~cm}^{-1}$, and the bands related to the stretching of $\mathrm{C}-\mathrm{N}, \mathrm{C}-\mathrm{O}, \mathrm{C}-\mathrm{C}$ groups in the range $1500-1200 \mathrm{~cm}^{-1}$ are visible. The GA spectrum is included as a reference in the inset.

The functionalization process was also visible on the film surface, as reported in Figure 3, due to the change in the colour of films. To complete the sensor fabrication, antibodies against E. coli $\mathrm{O} 157: \mathrm{H} 7$ were linked to the substrate as reported in Figure $2 \mathrm{c}$ and Figure 4 . For the final detection of E. coli O157:H7 this chip was immersed in a PBS buffer with $E$. coli O157:H7 (10 8 CFU/mL) for $30 \mathrm{~min}$, washed and analysed.

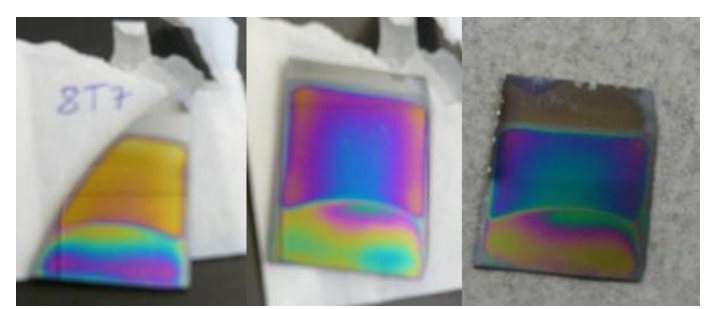

Figure 3: Titania films before functionalization (yellow), after APTES treatment (pink) and after the linking with GA (blue).

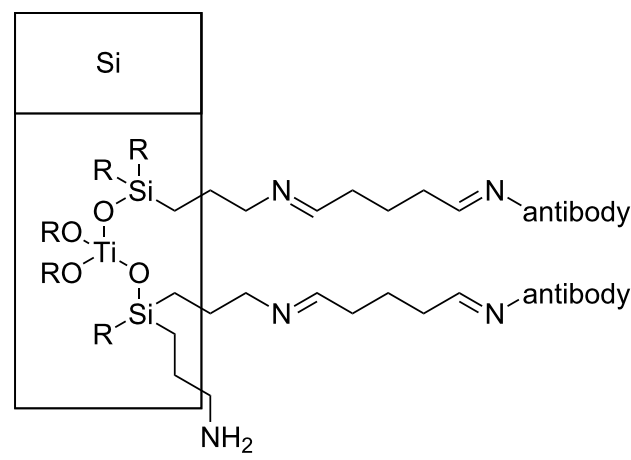

Figure 4: Structure of the chemical linking, $\mathrm{TiO}_{2}-\mathrm{APTES}-\mathrm{GA}-$ antibody.
The reported spectrum (Figure 2d) shows similar peaks for the film with the pathogen (dotted line) in comparison to films without the pathogen (solid line); however, new peaks appeared in particular in the regions $1300-2000 \mathrm{~cm}^{-1}$ (protein peaks of the bacterium), $3700-4000 \mathrm{~cm}^{-1}$ and $1200-800 \mathrm{~cm}^{-1}$ (signals of nucleic acids of the bacterium), which unfortunately in this region overlapped with the spectrum of the $\mathrm{Ab}$ and of the functionalized titania. The peaks in the $1630-1697 \mathrm{~cm}^{-1}$ region are due to amide I bands of the proteins in the cell and to their secondary structure. In the region $1402-1457 \mathrm{~cm}^{-1}$, bands due to carbohydrates, glycoproteins, lipids and their characteristic $\mathrm{C}-\mathrm{O}-\mathrm{H}$ in-plane bending peaks and $\mathrm{C}\left(\mathrm{CH}_{3}\right)_{2}$ symmetric stretching were present. Finally, in the range $900-1100 \mathrm{~cm}^{-1}$, peaks due to the DNA/RNA backbone and phosphate groups of nucleic acids due to the symmetric and asymmetric stretching of $\mathrm{P}=\mathrm{O}$ and $\mathrm{P}-\mathrm{O}-\mathrm{C}$ groups were visible. The spectrum of $E$. coli deposited on $\mathrm{Si}$ is provided as a reference in the inset.

\section{Detection of $E$. coli with other functionaliza- tion methods}

To understand the best method for pathogen capture, the direct absorption of the pathogens (E. coli O157:H7 and K12) on a titania thin film (Figure 5a), on films with only the specific antibody for E. coli O157:H7, and on films with APTES and Ab (Figure 5c) were tested. Figure 5a shows the FTIR spectra of different strains of E. coli (O157:H7 and K12) adsorbed onto the film surface with electrostatic interactions, illustrating that the substrate cannot discriminate between different strains and the different spectra of the pathogens are clearly visible. In contrast, in films with specific antibodies, only the binding of E. coli $\mathrm{O} 157: \mathrm{H} 7$ was visible and is reported in Figure 5b and 5c, although in films with APTES the presence of pathogens is poor.

Comparing the different immobilization techniques of detection (Figure 2 and Figure 5), the best result was obtained with the method that provided the covalent binding of the Ab on the film surface with APTES and GA (Figure 2d, dotted line), as expected. The other methods allowed the immobilization of bacteria, although not selectively, or with a low sensitivity of the device. In fact only the device shown in Figure 2 is selective and does not allow the linking of other subspecies of E. coli (E. coli $\mathrm{K} 12$ ), while on titania films (Figure 5a) it was possible to entrap pathogens with electrostatic interactions not differentiating between pathogens.

\section{Determination of the detection limits of $E$. coli O157:H7}

Tests to establish the detection limit of the device were carried out using serial dilutions of $E$. coli ranging in concentration from $1 \times 10^{8} \mathrm{CFU} / \mathrm{mL}$ to $10 \mathrm{CFU} / \mathrm{mL}$; the dilutions were valid- 


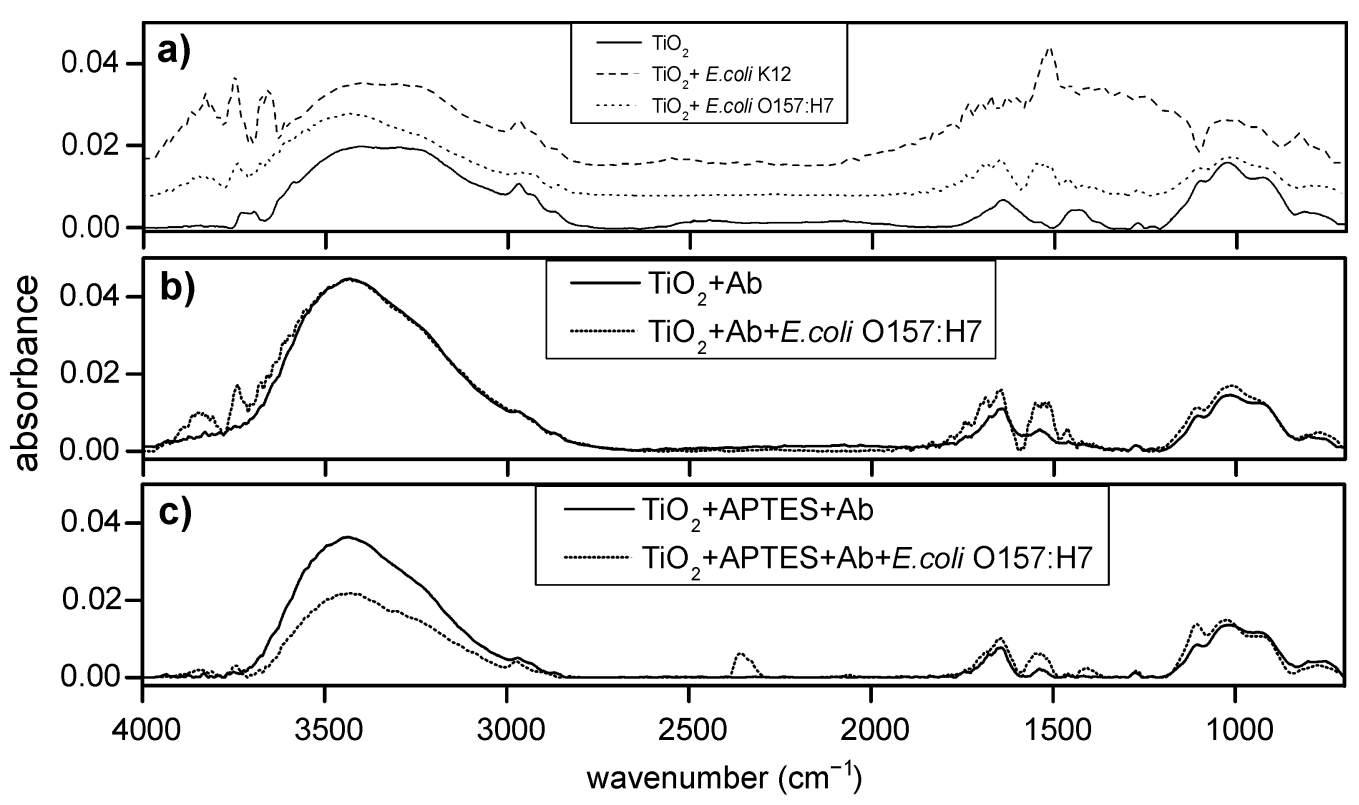

Figure 5: (a) FTIR spectrum of mesoporous titania films before (solid line) and after the immobilization of pathogens $E$. coli O157:H7 (dotted line) and E. coli K12 (dashed line). (b) FTIR spectrum of mesoporous titania films functionalized with anti-E. coli O157:H7-antibody (solid line) and after the immobilization of the pathogen (dotted line). (c) FTIR spectrum of titania films with APTES and antibody (solid line) and after the immobilization of E. coli (dotted line).

ated with the standard colony counting method (Figure 6) and DNA analysis was achieved by RT-PCR (Figure 7). These experiments were evaluated on mesoporous titania films functionalized with APTES-GA-anti-E. coli O157:H7-antibody, and a limit of detection of $1 \times 10^{2} \mathrm{CFU} / \mathrm{mL}$ (Figure 8) was achieved for $E$. coli $\mathrm{O} 157: \mathrm{H} 7$. A test with $E$. coli $\mathrm{K} 12$ was also carried out, but the spectrum of the functionalized chip did not

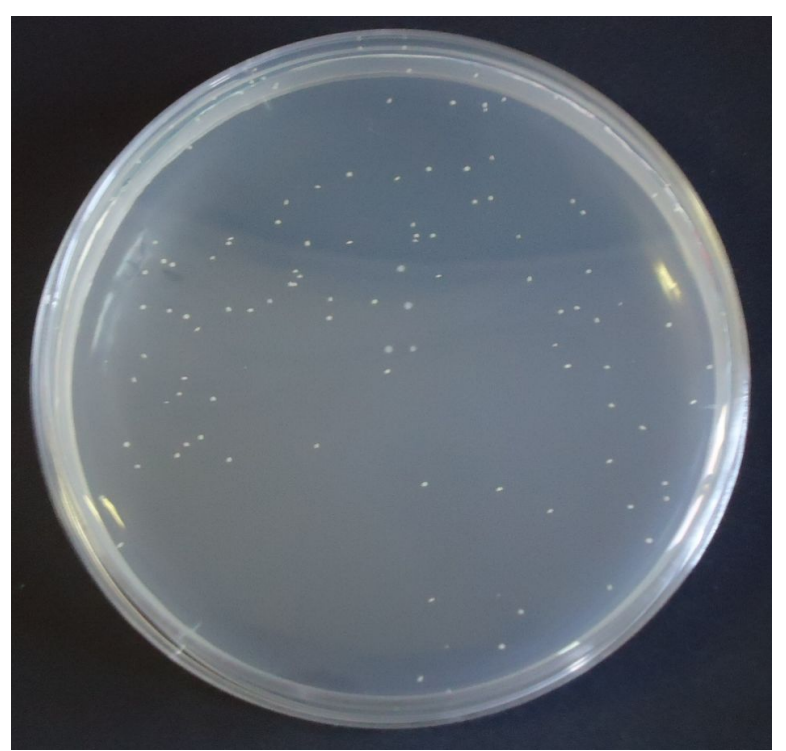

Figure 6: Colony counting method on a Petri plate with PCA and E. coli $\mathrm{O} 157: \mathrm{H} 7$ at a dilution of $10^{-6}$. show any peak due to this strain, because of the selectivity of the antibody, illustrating the specificity of the binding. Finally, colony micrographs of functionalized films after the immobilization of E. coli $\mathrm{O} 157: \mathrm{H} 7$ at different concentrations were collected with an optical microscope (Figure 9).

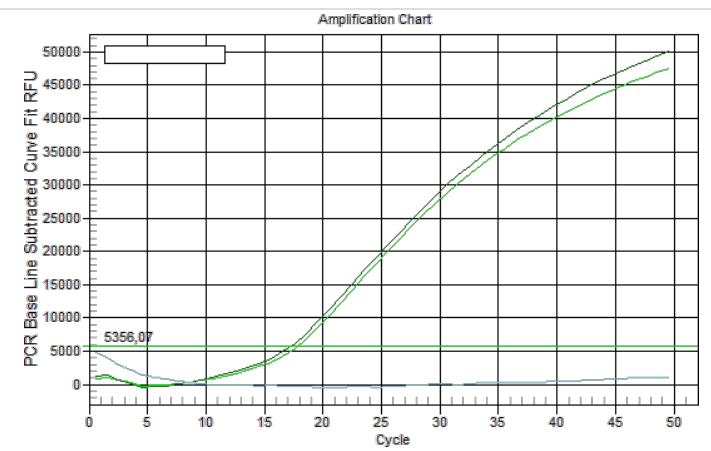

Figure 7: RT-PCR of DNA extracted from the nutrient broth. The blue line is the blank, the light green curve is the reference sample and the green curve is the DNA analysed.

\section{Conclusion}

The detection of E. coli O157:H7 by using an FTIR platform, through the linking of specific antibodies to mesoporous titania thin films was demonstrated. Cross-linking tethers were used to immobilize antibodies effectively through a chemical method. E. coli $\mathrm{O} 157: \mathrm{H} 7$ was identified and classified with standard methods and according to its infrared signature. Nanomaterials used for the immobilization and detection of pathogens, enabled 


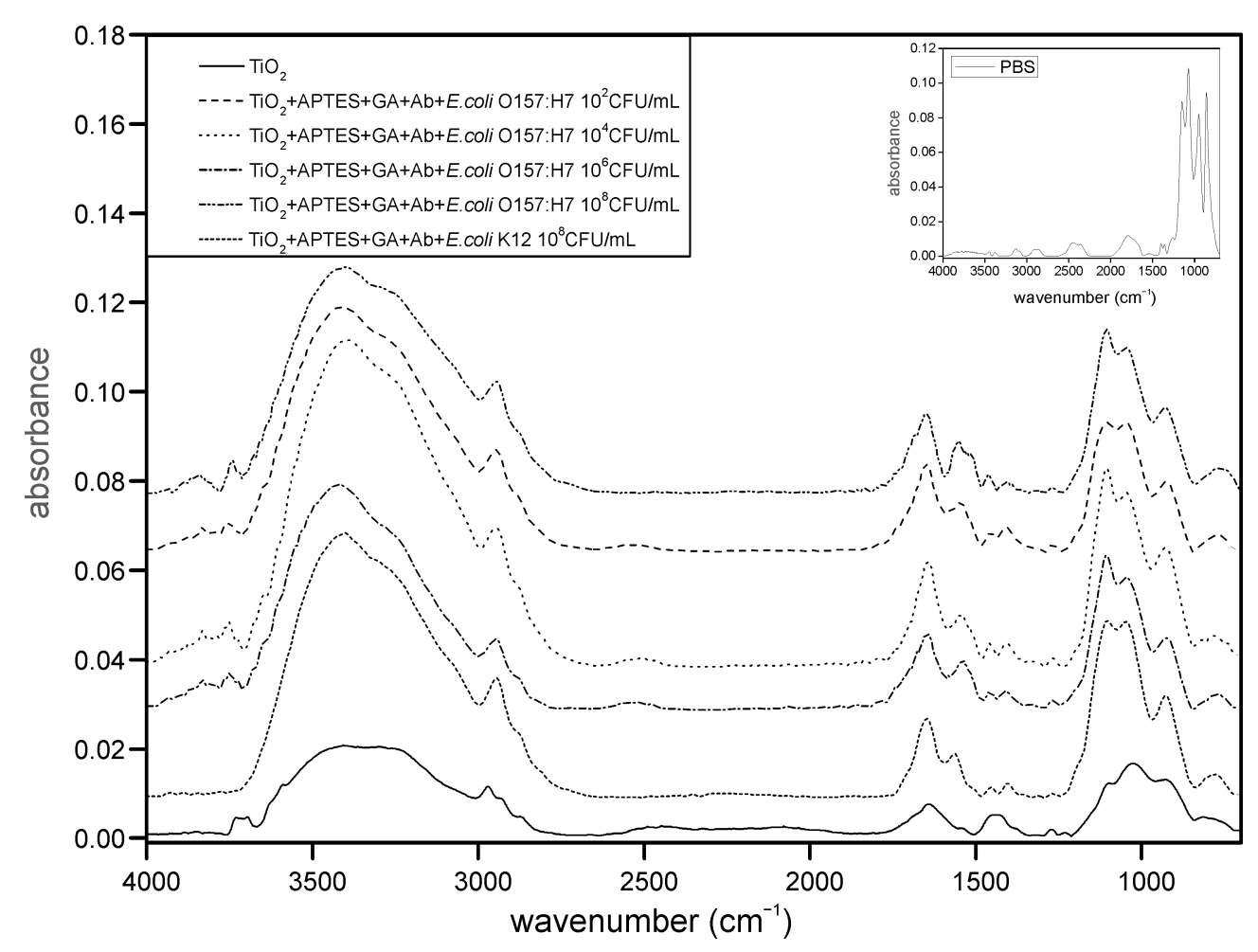

Figure 8: FTIR spectra of titania films alone (solid line) and functionalized with APTES-GA-anti-E. coli O157:H7-Ab after exposure to different concentrations of $E$. coli $\mathrm{O} 157: \mathrm{H} 7\left(10^{8}-10^{2} \mathrm{CFU} / \mathrm{mL}\right)$ and $E$. coli $\mathrm{K} 12\left(10^{8} \mathrm{CFU} / \mathrm{mL}\right)$ in order from the top to the bottom. The negative control of PBS is reported in the inset.

the possible capture of $E$. coli in less than $30 \mathrm{~min}$. The benefit of this approach is specificity due to the antibodies and the characteristic fingerprint of the pathogens. In this way we demonstrated, as with the new biosensor, through a FTIR meas-

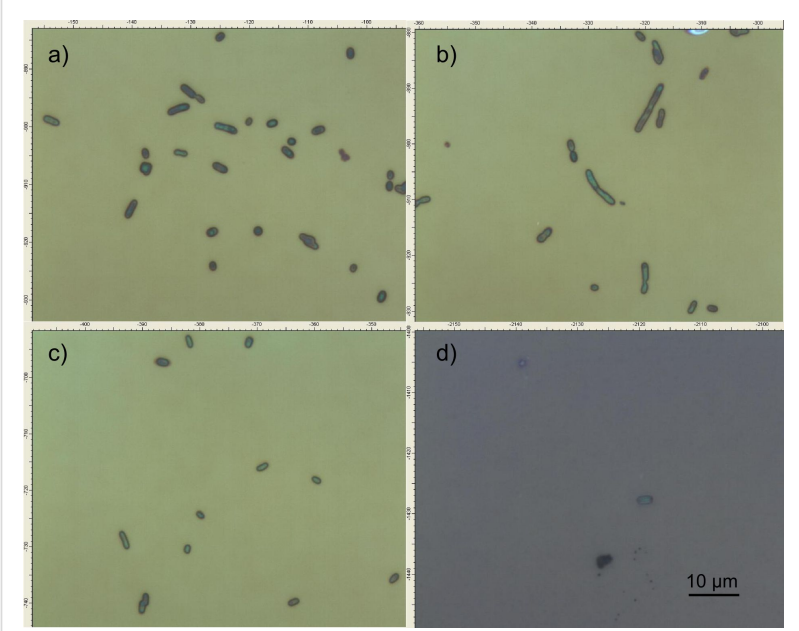

Figure 9: Colony micrographs of $E$. coli $\mathrm{O} 157: \mathrm{H} 7$ immobilized on mesoporous titania films functionalized with APTES-GA-anti-E. coli 0157:H7-Ab, after exposure to different concentrations of $E$. coli O157:H7. (a) $10^{6} \mathrm{CFU} / \mathrm{mL}$; (b) $10^{4} \mathrm{CFU} / \mathrm{mL}$; (c) $10^{2} \mathrm{CFU} / \mathrm{mL}$; (d) $10 \mathrm{CFU} / \mathrm{mL}$. urement and a short time for the analysis, that it is possible to discriminate in a selective manner whether a water sample is contaminated with E. coli O157:H7. This proposed device can also be adapted for in-field analysis if treated titania films, designed for specific pathogens, can be integrated with portable instruments for the direct assessment of pathogenic contaminants in food systems.

\section{Acknowledgements}

This work was a collaboration between the University of Sassari, the University of Milan and the Center for Food Safety Engineering at Purdue University. The project was financed by Legge 7, Regione autonoma della Sardegna, IDRISK Project. Thanks are given to Reeta Davis, Purdue University and Porto Conte ricerche for the use of instruments and to Dr. Lollai of the Istituto zooprofilattico Sassari.

\section{References}

1. Ivnitski, D.; Abdel-Hamid, I.; Atanasov, P.; Wilkins, E. Biosens. Bioelectron. 1999, 14, 599-624. doi:10.1016/S0956-5663(99)00039-1

2. Chemburu, S.; Wilkins, E.; Abdel-Hamid, I. Biosens. Bioelectron. 2005, 21, 491-499. doi:10.1016/j.bios.2004.11.025

3. Alocilja, E. C.; Radke, S. M. Biosens. Bioelectron. 2003, 18, 841-846. doi:10.1016/S0956-5663(03)00009-5 
4. Buchanan, R. L.; Doly, M. P. Food Technol. 1997, 51, 69-76.

5. Rowe, P. C.; Orrbine, E.; Wells, G. A.; McLaine, P. N. J. Pediatr. 1991, 119, 218-224. doi:10.1016/S0022-3476(05)80730-9

6. Leonard, P.; Hearty, S.; Brennan, J.; Dunne, L.; Quinn, J.; Chakraborty, T.; O'Kennedy, R. Enzyme Microb. Technol. 2003, 32, 3-13. doi:10.1016/S0141-0229(02)00232-6

7. de Boer, E.; Beumer, R. R. Int. J. Food Microbiol. 1999, 50, 119-130. doi:10.1016/S0168-1605(99)00081-1

8. Velusamy, V.; Arshak, K.; Korostynska, O.; Oliwa, K.; Adley, C. Biotechnol. Adv. 2010, 28, 232-254. doi:10.1016/j.biotechadv.2009.12.004

9. Iqbal, S. S.; Mayo, M. W.; Bruno, J. G.; Bronk, B. V.; Batt, C. A.; Chambers, J. P. Biosens. Bioelectron. 2000, 15, 549-578. doi:10.1016/S0956-5663(00)00108-1

10. Brooks, B. W.; Devenish, J.; Lutze-Wallace, C. L.; Milnes, D.; Robertson, R. H.; Berlie-Surujballi, G. Vet. Microbiol. 2004, 103, 77-84. doi:10.1016/j.vetmic.2004.07.008

11. Touron, A.; Berthe, T.; Pawlak, B.; Petit, F. Res. Microbiol. 2005, 156, 541-553. doi:10.1016/j.resmic.2005.01.001

12. Murphy, N. M.; McLauchlin, J.; Ohai, C.; Grant, K. A. Int. J. Food Microbiol. 2007, 120, 110-119. doi:10.1016/j.ijfoodmicro.2007.06.006

13. Ravindranath, S. P.; Mauer, L. J.; Deb-Roy, C.; Irudayaraj, J. Anal. Chem. 2009, 81, 2840-2846. doi:10.1021/ac802158y

14. Schemberg, J.; Grodrian, A.; Römer, R.; Gastrock, G.; Lemke, K. Phys. Status Solidi A 2010, 207, 904-912. doi:10.1002/pssa.200983315

15. Varshney, M.; Li, Y.; Srinivasan, B.; Tung, S. Sens. Actuators, B 2007, 128, 99-107. doi:10.1016/j.snb.2007.03.045

16. Zhu, Y.; Koh, W. C. A.; Shim, Y.-B. Electroanalysis 2010, 22, 2908-2914. doi:10.1002/elan.201000394

17. Mello, L. D.; Kubota, L. T. Food Chem. 2002, 77, 237-256. doi:10.1016/S0308-8146(02)00104-8

18. Pérez-López, B.; Merkoçi, A. Trends Food Sci. Technol. 2011, 22, 625-639. doi:10.1016/j.tifs.2011.04.001

19. Arora, P.; Sindhu, A.; Dilbaghi, N.; Chaudhury, A. Biosens. Bioelectron. 2011, 28, 1-12. doi:10.1016/j.bios.2011.06.002

20. Su, L.; Jia, W.; Hou, C.; Lei, Y. Biosens. Bioelectron. 2011, 26, 1788-1799. doi:10.1016/j.bios.2010.09.005

21. Sakamoto, C.; Yamaguchi, N.; Yamada, M.; Nagase, H.; Seki, M.; Nasu, M. J. Microbiol. Methods 2007, 68, 643-647. doi:10.1016/j.mimet.2006.11.003

22. Lazcka, O.; Del Campo, F. J.; Muñoz, F. X. Biosens. Bioelectron. 2007, 22, 1205-1217. doi:10.1016/j.bios.2006.06.036

23. Liu, Y.; Li, Y. Anal. Chem. 2001, 73, 5180-5183. doi:10.1021/ac0104936

24. Wolter, A.; Niessner, R.; Seidel, M. Anal. Chem. 2008, 80, 5854-5863. doi:10.1021/ac800318b

25. Acharya, G.; Chang, C.-L.; Savran, C. J. Am. Chem. Soc. 2006, 128, 3862-3863. doi:10.1021/ja057490I

26. Mura, S.; Greppi, G. F.; Roggio, A. M.; Malfatti, L.; Innocenzi, P. Microporous Mesoporous Mater. 2011, 142, 1-6. doi:10.1016/j.micromeso.2010.10.047

27. Sivakesava, S.; Irudayaraj, J.; DebRoy, C. Trans. ASABE 2004, 7, 951-957.

\section{License and Terms}

This is an Open Access article under the terms of the Creative Commons Attribution License

(http://creativecommons.org/licenses/by/2.0), which permits unrestricted use, distribution, and reproduction in any medium, provided the original work is properly cited.

The license is subject to the Beilstein Journal of Nanotechnology terms and conditions: (http://www.beilstein-journals.org/bjnano)

The definitive version of this article is the electronic one which can be found at:

doi:10.3762/bjnano.3.55 